\title{
Investigating the Relationship between Work-family Enrichment and Psychological Well-being: The Mediating Role of Meaningful Work.
}

\author{
Dr. NOSHEEN SARWAT \\ (Corresponding Author) \\ Bahauddin Zakariya University. \\ Email: nosheensarwat@bzu.edu.pk \\ Dr. AMMAR HUSSAIN \\ Karakoram International University, Gilgit. \\ Email: dr.ammar@kiu.edu.pk \\ Dr. TARIQ IQBAL KHAN \\ Assistant Professor, Department of Management Sciences \\ The University of Haripur, Pakistan. \\ Email: tariqfirst@gmail.com
}

\begin{abstract}
Competitive pressures and dynamic workplaces have presented individuals with numerous challenges at the work place. Work seems more like a necessity and lacks passion and purpose and meaning. Moreover, unemployment rates in developing countries force individuals to take up work in which they are not even interested. The present study investigated the effect of work to family enrichment (WFE) on psychological well-being of individuals through the mediating role of meaningful work based on the assumptions of spillover theory. Resources acquired at work enrich individual's family life which make work look more meaningful and in turn has positive consequences for psychological health of an individual. The unit of analysis for this study was individuals working in various banks of Pakistan. Data were collected from 215 full time bankers working in public and private banks of Pakistan. Banking industry was chosen in part due to its complex nature and further because of the lucrative incentives and training and development it offers to individuals working for these banks. Data were analyzed using model 4 given in PROCESS MACRO based on bootstrapping which is considered one of the best techniques for mediation analysis. Results supported all the hypotheses of this study. Based on the findings of this study, it was concluded that work should be designed in such a way that it enriches the family life of individuals, this creates a purpose and meaning in work and has positive consequences for the psychological health of individuals.
\end{abstract}

Keywords: Work-Family Enrichment, Meaningful Work, Psychological Well-Being, Spillover Theory.

\section{Introduction}

The work and family literature has been mainly dominated by the conflict perspective based on the scarcity hypothesis which articulates that individuals who assume multiple roles in their lives like family roles and work roles are prone to conflict because they cannot fulfill responsibilities of each of the roles and this may cause conflict (Greenhaus \& Parasuraman, 1999). However another aspect of the work family interface has been based on the expansion hypothesis which states that assuming multiple roles can have various advantages as well which outweigh the disadvantages created by assuming multiple roles. The expansion hypothesis, previously ignored now has attracted the attention of organizational researchers and scholars, 
specifically after Greenhaus's work family enrichment theory in which he and Powell explicitly state that work and family can be in alignment too (Greenhaus \& Powell, 2006). Recognizing the obsession of the conflict perspective in the work-family interface research, researchers have urged for a more adjusted approach in recent reviews that focuses on the positive aspects of uniting the work and domestic roles which individuals have towards their family (Greenhaus \& Parasuraman, 1999). Researchers suggest that individuals who assume multiple roles and who are also satisfied with these roles experience greater satisfaction and psychological well-being as compared to individuals who assume only one role and are dissatisfied with that particular role. Also participation in multiple roles can help mitigate the negative effects of one of the roles by focusing on the other role (Greenhaus \& Powell, 2006). For example stress in the family role can be relieved by diverting all attention to work and in the similar domain stress at work can be relieved when one spends quality time with family members.

Though participation in multiple roles often known as role accumulation has multiple advantages and the benefits of assuming multiple roles is well documented in literature still there are multiple ways in which this role accumulation can benefit individuals for example there is an additive effect of the work role and family role on the well-being of an individual. Several research studies have demonstrated that role accumulation can have beneficial effects on the physical and psychological well-being of individuals working in organizations (Barnett \& Hyde, 2001). In addition to this if the role is of high quality, individuals have also reported additive effects on happiness, satisfaction with life, and quality of life (Rice, Frone, \& Mc Farlin, 1992). One can also argue that by participating in multiple roles, an individual is engaging in multiple meaningful activities to perform these roles which can have a positive effect on the overall well-being of that individual (Hooker et al., 2020). Based on these findings it is suggested that when individuals particularly feel that their work has helped them achieve their family objectives due to the positive spillover of resources from work to family as suggested by spillover theory (Staines, 1980), they feel that their family lives have been enriched which makes work seem more meaningful and purposeful thereby enhancing their psychological well-being. In collectivist cultures like Pakistan, where individuals are a part of extended families and they have to balance multiple roles, it's imperative that work is seen as contributing meaning and purpose to life. This is only possible when the experiences that individuals gain in work life improve the quality of experiences gained in family life. When individuals see work as a source of enriching their family lives, they find their work meaningful since it will be seen as a source of improving the quality of family life and meaningful work in return enhances their psychological health.

\section{Objectives of the Study}

The main objective of this research is to study the mechanism through which work-family enrichment (WFE) leads to psychological well-being of an individual through meaningful work based on the postulates of social exchange theory. It attempts to answer the following research questions:

RQ1: What is the connection between WFE and psychological well-being?

RQ2: What is the connection between WFE and meaningful work?

RQ3: What is the relationship between meaningful work and psychological well-being?

RQ4: Does meaningful work mediate the relationship between WFE \& psychological well-being?

\section{Literature Review}

\section{Work to family enrichment and meaningful work}

Work to family enrichment is an important aspect of the work-life interface where work is seen as an ally of family and a source of enrichment in the family life of an individual. In work-family enrichment theory, work-family enrichment is defined as the degree to which certain occurrences and experiences in one domain like work role progress the quality of life in another domain like family (Greenhaus \& Powell, 2006). Work and family both can be related. There are different perspectives which explain that work 
affects the family and family affects the work and that they are interrelated. There is a proper need for understanding of the issue that people have been working and they have been not giving time to their family. On the other hand, some people are very effective in maintaining work and family.

A person works in order to achieve a better quality of life, but due to lack of proper personal management, that specific person is not able to manage the family. The author explains three different scenarios in order to solve the issue. According to him, the first person manages the house of the work and has divided the time. On the other hand, there is a second person who has been giving time to the work but not to the family due to which there has been an increase in a family issue. This person is more focused on the family; he lives in stress as the workload increase. Hence in both conditions, people need to maintain their relation between work and the family. This will ultimately be developed in the form of work-family enrichment (Greenhaus, 2006).

Work is seen as a facilitation process which improves the quality of family life of an individual. Traditional focus of the work family interface has always seen work as source of conflict in an individual's family life however, it is imperative to understand that now organizational scholars are emphasizing more on the positive side of the work family interface. A number of research studies have been conducted on the relationship between work-family enrichment and job related attitudes and behaviors. In a study conducted by Chan and colleagues, it was observed that work-family enrichment improved job satisfaction through the mediating mechanisms of work-life balance and self-efficacy (Chan, et al., 2016). Psychological wellbeing is a state in which individuals are free from distress and have positive associations with other people like their family members and work colleagues (Ryff, 1995). Numerous research studies have shown that resources gained in one domain improve the mental and physical well-being of individuals when those resources are utilized in another domain (cf Carlson et al., 2011; Jaga et al., 2013). This discussion forms the basis for the first hypothesis of this study:

Hypothesis 1: There is a positive relation between work-family enrichment and psychological well-being

Mediating role of meaningful work between work-family enrichment and psychological well-being

Individuals should be free from distress and mental problems to be psychologically well and they should also find a positive meaning in their life and in relations (Ryff, 1995). The key dimensions of the model of well-being presented by Ryff are self-acceptance, positive relationships with other people and having a purpose in life etc. Self-acceptance is a kind of characteristic in which the individual has positive attitudes towards oneself. It also means accepting the good or worse characteristics an individual possesses and also accepting of what one has done in the past.. These dimensions comprise wellness that includes a positive evaluation of one's life, a feeling of continued growth as a person, the belief that life is meaningful, good relationships with others, the competence to manage one's life effectively, and a sense of self-determination (Ryff, 1995). If individuals are to be psychologically well then the relations they have with others is an important predictor of their mental and physical health. In people's work and family domain, there are a number of relations which can positively or negatively affect the health life of an individual. The experiences an individual gain's in work life affect the quality of his/her family life. In the work family interface, Staines (1980) was the first to argue that emotions and cognitions developed at work are not confined to the work place and similarly emotions and cognitions developed at home are not limited to home, rather the experiences gained from one domain cross the boundaries (both physical and temporal) of one domain and spillover to the other domain. These experiences can be positive from work domain to family domain and from family domain to work domain. For example work resources and opportunities can help to improve better functioning of the home domain (Barnett, 2005). Similarly the work-family interface can have negative consequences when strains from work can affect an individual's family life (Bellavia et al., 2005). 
The spillover theory (Staines, 1980) has been used by a number of researchers to explain the transference of quality experiences at work to the family domain. Work-family enrichment is the term devised by Greenhaus and Powell to explain that quality experiences in one domain can improve the experiences we gain in another domain because the positive skills and experiences we gain in one role i.e. work role help us to improve the experiences of the other role i.e. family role (Greenhaus \& Powell, 2006). Similarly we argue that when individuals feel that work has been a source of enrichment in their family lives then they will find more purpose and meaning in their work lives. Work is meaningful when an individual perceives it as valuable and worthwhile (Hackman \& Oldham, 1976). Experienced meaningfulness is an integral part of the job characteristics model which postulates meaningfulness as a psychological state which mediates the relationship between work characteristics and workplace outcomes (Hackman \& Oldham, 1976). When individuals feel that family life has improved due to the skills and abilities they acquired at work, they will consider their work more meaningful. Based on Hackman \& Oldham's understanding of meaningfulness, Steger et al., (2012) stated that when work is meaningful it can have positive associations with an individual's life satisfaction and psychological health. According to a Meta-analysis, people who work in professions they love have reported higher levels of job satisfaction and increased performance. For such individuals work is more meaningful and meaningful work has several positive outcomes. Meaningful work adds purpose and existence to one's life which in turns has positive consequences for an individual's psychological well-being (Allan, 2019). Based on the above theory and evidence from literature it can be hypothesized that,

Hypothesis 2: There is a positive association between WFE and meaningful work Hypothesis 3: There is a positive association between meaningful work and psychological well-being Hypothesis 4: Meaningful work mediates the association between WFE and psychological well-being

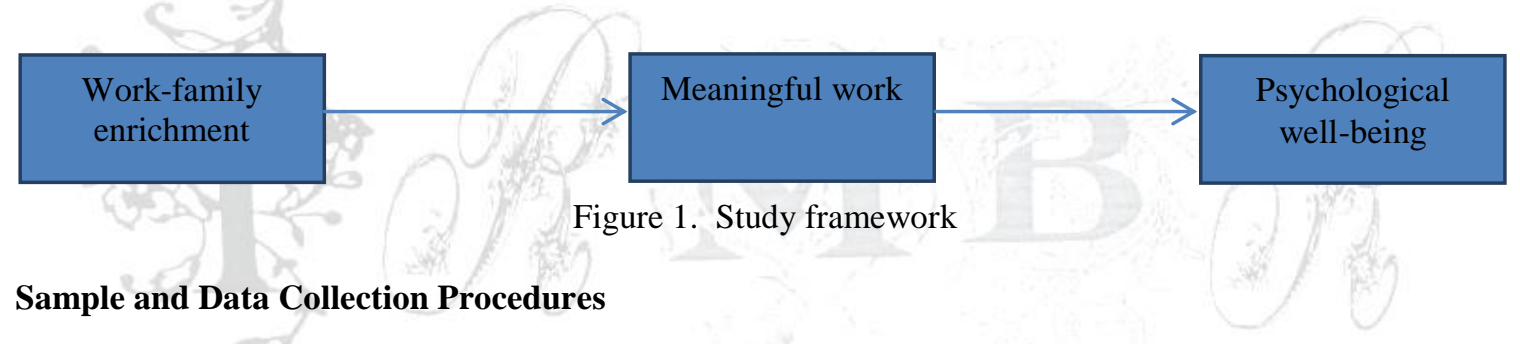

Data were collected from a full time banking employees working in various public and private banks of Pakistan. Banking industry was selected because of its dynamic and competitive nature. Researchers have argued that the banking industry of Pakistan is currently facing fierce competition due to which they are introducing new products and services (Mohsan et al., 2011) and this has created multiple pressures on individuals working for these organizations. Individuals working for banks face numerous work pressures in the form of work load and time pressures as well. Under the circumstances balancing work and family roles is a challenging task for them. Banking professionals were targeted for the reason that they are mostly MBA's by training and are expected to comprehend the questionnaire in English. Multiple researchers in Pakistan have collected data from banking professionals and one of the main reasons reported by them is that individuals working for banks can easily understand English (cf Sarwat \& Shahzad, 2017; Qureshi et al., 2020). The employees were asked to complete the survey which contained questions related to workfamily enrichment, felt obligation and meaningful work. All measures were self-report. Participation in the survey was voluntary and we also requested for demographic comprising of age, gender, education and experience. All participants were also assured of the confidentiality of the data.

A total of 300 questionnaires were distributed 248 responses were received. However, due to missing data we had to exclude 33 questionnaires. Hence the final response rate was $71.66 \%$ comprising of 215 filled questionnaires. The majority of respondents $(77.6 \%)$ were males with an average age of 33 years (SD = 5.3) see Table 1 . The sample included $65 \%$ frontline supervisors, $35 \%$ middle managers and $10 \%$ senior 
managers. Average experiences was $4.30(\mathrm{SD}=1.8$.) years. About $82 \%$ of the respondents had a master's degree and $18 \%$ were having MS degrees.

\section{Measures}

All the constructs of this study were measured using self-reported instruments and assesses on a five-point likert scale where 1 represented strongly disagree and 5 represented strongly agree. All reliabilities of the measures used were according to acceptable standards i.e. above 0.7 .

Work-family enrichment: WFE was measured on a five point Likert scale. This scale was developed by Kacmar et al., (2014). It has total 9 items Sample items were "My involvement in my work gives me a sense of success and aids me in becoming a better member of my family". Cronbach alpha of this scale was (0.82).

Meaningful work: This variable was measured by the scale used by May and colleagues in their study on meaningful work (May et al., 2004) and included six items. A 5-point likert scale was used to measure responses. Sample items included "The work I do on this job is very important to me" and "The work I do on this job is worthwhile". Alpha reliability of this scale was $(0.85)$

Psychological well-being: We assessed psychological well-being with Ryff (1995) scale comprising of 12items. Responses were captured on a 5-point likert scale. Example items included "I feel constantly under stress" and "I have been losing confidence in myself". Internal consistency of this scale was $(0.79)$

\section{Results}

Table 1 depicts details related to the correlations between study variables, means, standard deviations and internal consistency of the study variables have been presented in parenthesis. All correlations were in the expected directions. The correlation between work-family enrichment and psychological well-being is $(\mathrm{r}=0.146, \mathrm{p}<.05)$, work family enrichment and meaningful work is $(\mathrm{r}=0.367, \mathrm{p}<.01)$, meaningful work and psychological well-being $(r=0.182, \mathrm{p}<.05)$.

Table 1 shows the descriptives, correlations and values for internal consistency

\begin{tabular}{|c|c|c|c|c|c|c|c|c|}
\hline & Mean & SDV & Age & Gender & $\begin{array}{l}\text { Experi } \\
\text { ence }\end{array}$ & $\begin{array}{l}\text { Work- } \\
\text { family } \\
\text { enrichment }\end{array}$ & $\begin{array}{l}\text { Meaningful } \\
\text { work }\end{array}$ & $\begin{array}{l}\text { Psychological } \\
\text { well-being }\end{array}$ \\
\hline Age & 33.08 & 5.34 & - & & & & & \\
\hline Gender ${ }^{1}$ & 1.23 & .421 & $-.281^{* *}$ & - & & & & \\
\hline Experience & 5.40 & 1.8 & $.649^{* *}$ & $-.215^{* *}$ & - & & & \\
\hline $\begin{array}{l}\text { Work-family } \\
\text { enrichment }\end{array}$ & 4.51 & 0.51 & -0.122 & 0.12 & -0.145 & $(0.82)$ & & \\
\hline Meaningful work & 4.26 & 0.75 & 0.086 & -0.028 & -0.097 & $.367 * *$ & $(0.85)$ & \\
\hline $\begin{array}{l}\text { Psychological } \\
\text { Well- Being }\end{array}$ & 4.67 & .52 & $.207 *$ & -0.112 & $.221^{*}$ & $0.146^{*}$ & $0.182 *$ & $(0.79)$ \\
\hline
\end{tabular}

Note: alpha reliabilities estimates have been given in parentheses. $* \mathrm{p}<.05 ; * * \mathrm{p}<.01$. 


\section{Mediation Analysis}

To understand the mechanism through which an independent variable affects a dependent variable, researchers have often used the multiple steps approach guidance provided by Barron \& Kenney (1986). This approach involves three steps. Step 1 is that the IV and DV should be related. In Step 2 the IV and mediator should be related and the mediator and DV should be related. Methodologists like Shrout \& Bolger (2002) however have argued that for the mediating mechanism to be effective, it is not necessary that the independent variable and dependent variable should be related to each other. Latest technique for assessing mediation is bootstrapping. It has been argued that bootstrapping aids in overcoming the shortcomings associated with non-normal sampling distributions in mediation analysis. In this study we have used the PROCESS macro provided by Preacher \& Hayes (2004) to assess mediation. We used model 4 to assess mediation.

Table 2: Results for mediation analysis of meaningful work

\begin{tabular}{|c|c|c|c|c|}
\hline Variable & B & SE & $\mathbf{t}$ & $P$ \\
\hline & \multicolumn{4}{|c|}{ Direct \& total effects } \\
\hline Meaningful work on work to family enrichment & 0.16 & 0.13 & 4.36 & .000 \\
\hline Psychological well-being on meaningful work & 0.13 & 0.05 & 6.14 & .045 \\
\hline $\begin{array}{l}\text { Psychological well-being on work to family } \\
\text { enrichment }\end{array}$ & 0.10 & 0.04 & 5.21 & .025 \\
\hline Bootstrap results & Boot & SE & $\begin{array}{l}\text { Boot LL } \\
95 \% \mathrm{CI}\end{array}$ & $\begin{array}{c}\text { Boot UL } \\
5 \% \mathrm{CI}\end{array}$ \\
\hline Effect & 0.132 & 0.042 & 0.041 & 0.210 \\
\hline
\end{tabular}

$\mathrm{N}=215$. Bootstrap sample size $=5000$. LL represents lower limit. UL represents upper limit. CI represents confidence interval

Table 2 provides the result for hypotheses $1,2,3$ and 4 . Work-family enrichment was positively related to meaningful work $(\mathrm{B}=0.16, \mathrm{p}<.001)$. Meaningful work had a positive association with psychological wellbeing $(\mathrm{B}=-0.13, \mathrm{p}<.05)$. Work-family enrichment also had a positive relationship with psychological well-being $(\mathrm{B}=-0.10, \mathrm{p}<.05)$. Hence hypotheses 1,2 and 3 were accepted. The mediation hypothesis was also accepted. Bootstrap results indicated (Table 2), with a bootstrapped 95\% Confidence interval the indirect effect of WFE on psychological well-being through meaningful work did not contain a zero value $(0.041,0.210)$.

All scales were self-report so there was a possibility of common method bias (Podsakoff et al., 2003). There are numerous ways which methodologists have suggested for assessing common method variance. One possible method is the Herman single factor test in which all items of the constructs of the study are allowed to load on a single factor and the total variance explained by all these factors combined should be less that $20 \%$. When we loaded all items on a single factor, the total variance explained was less than $15 \%$ indicating that common method variance was not a threat to internal identity of this study.

\section{Discussion}

The purpose of this study was to study the relation between work family enrichment, meaningful work and psychological well-being of individuals working in the banking industry of Pakistan. The findings of this study supported the mediating role of meaningful work between work-family enrichment and psychological wellbeing. Work is an integral part of an individual's life and specifically in developing countries where unemployment is soaring high, work becomes more like a necessity and individuals feel destitute without it. However, if with the help of this work individual's support their families then they feel more self-reliant. The skills, resources acquired at work help working individuals enrich their families due to which 
individuals understand the purpose and worth of their work and then work is seen as more meaningful and worthwhile. The positive consequences of having a positive meaning and purpose in life are welldocumented in literature. Engaging in multiple roles gives individual a chance to perform various meaningful activities which contributes to their well-being (cf Hooker et al., 2020) and meaningful work has positive consequences for mental and physical health of individuals (Dich et al., 2019). The results reported by this study are in accordance with the same stream of research. A number of researchers have argued that higher levels of perceptions of meaningful work result in lower level of exhaustion and enhanced well-being (Kim \& Beehr, 2018). The main strength of this study is to understand the psychological mechanism through which work to family enrichment can enhance an individual's psychological well-being through meaningful work. Researchers have already tested the direct relationship between work to family and family to work enrichment on job satisfaction through job related well-being (Chan et al., 2020), however in this study we have argued that meaningful work can also act as a psychological mechanism for understanding the relationship between work family enrichment and psychological well-being.

\section{Limitations and Future Research Trajectories}

There are a few limitations to this study, like the cross sectional nature and homogeneous nature of the sample from which data was collected. Future trajectories can investigate the above relationships in diverse samples and also examine dispositional or contextual moderators like one's leader and his/her role in enhancing the meaningfulness at work. The competitive and dynamic nature of the banking industry of Pakistan has created multiple pressures for the individuals associated with this industry. One of the challenges employees of banks face is to balance their work and family lives. Though bankers do get lucrative pay packages and other benefits but time based conflicts can result in compromise of one of the roles work or family. The findings of this study suggest that the jobs of these bankers should be designed as such that the skills and abilities, individuals acquire at work help them to enrich their family lives. In that case, individuals will find their work more meaningful and worthwhile and it will also affect their psychological well-being.

\section{References}

Allan, B. A., Batz-Barbarich, C., Sterling, H. M., \& Tay, L. (2019). Outcomes of meaningful work: A meta-analysis. Journal of management studies, 56(3), 500-528.

Baron, R. M., \& Kenny, D. A. (1986). The moderator-mediator variable distinction in social psychological research: Conceptual, strategic, and statistical considerations. Journal of personality and social psychology, 51(6), 1173-1182.

Bellavia, G. M., Frone, M. R., Barling, J., \& Kelloway, E. K. (2005). Handbook of work stress. WorkFamily Conflict. Canada: Thousand Oaks, 113-147.

Carlson, D. S., Ferguson, M., Kacmar, K. M., Grzywacz, J. G., \& Whitten, D. (2011). Pay it forward: The positive crossover effects of supervisor work-family enrichment. Journal of Management, 37(3), 770789.

Chan, X. W., Kalliath, P., Chan, C., \& Kalliath, T. (2020). How does family support facilitate job satisfaction? Investigating the chain mediating effects of work-family enrichment and job-related well-being. Stress and Health, 36(1), 97-104.

Chan, X. W., Kalliath, T., Brough, P., Siu, O. L., O'Driscoll, M. P., \& Timms, C. (2016). Work-family enrichment and satisfaction: The mediating role of self-efficacy and work-life balance. The International Journal of Human Resource Management, 27(15), 1755-1776. Retrieved from https://www.tandfonline.com/doi/abs/10.1080/09585192.2015.1075574

Dich, N., Lund, R., Hansen, Å. M., \& Rod, N. H. (2019). Mental and physical health effects of meaningful work and rewarding family responsibilities. PloS one, 14(4), e0214916.

Greenhaus, J. (2006). Enrichment, When Work And Family Are Allies: A Theory Of Work-Family. Researchgate, 72-92. 
Greenhaus, J. H., \& Parasuraman, S. (1999). Research on work, family, and gender: Current status and future directions.

Hackman, J. R., \& Oldham, G. R. (1976). Motivation through the design of work: Test of a theory. Organizational behavior and human performance, 16(2), 250-279.

Hooker, S. A., Masters, K. S., Vagnini, K. M., \& Rush, C. L. (2020). Engaging in personally meaningful activities is associated with meaning salience and psychological well-being. The Journal of Positive Psychology, 15(6), 821-831.

Jaga, A., Bagraim, J., \& Williams, Z. (2013). Work-family enrichment and psychological health. SA Journal of Industrial Psychology, 39(2), 1-10.

Kacmar, K. M., Crawford, W. S., Carlson, D. S., Ferguson, M., \& Whitten, D. (2014). A short and valid measure of work-family enrichment. Journal of Occupational Health Psychology, 19(1), 32.Barnett, R. C., \& Hyde, J. S. (2001). Women, men, work, and family: An expansionist theory. American psychologist, 56(10), 781.

Kim, M., \& Beehr, T. A. (2018). Organization-based self-esteem and meaningful work mediate effects of empowering leadership on employee behaviors and well-being. Journal of Leadership \& Organizational Studies, 25(4), 385-398.

May, D. R., Gilson, R. L., \& Harter, L. M. (2004). The psychological conditions of meaningfulness, safety and availability and the engagement of the human spirit at work. Journal of occupational and organizational psychology, 77(1), 11-37.

Mohsan, F., Nawaz, M. M., Khan, M. S., Shaukat, Z. and Aslam, N. (2011). Impact of customer satisfaction on customer loyalty and intentions to switch: evidence from banking sector of Pakistan. International Journal of Business and Social Science, 230-245

Podsakoff, P.M., Mackenzie,S.b., \& Podsakoff,N.P.(2003). Common method bias in behavioral research: A critical review of the literature and recommended remedies. Journal of Applied Psychology,88, 879903.

Preacher, K. J., \& Hayes, A. F. (2004). SPSS and SAS procedures for estimating indirect effects in simple mediation models. Behavior research methods, instruments, \& computers, 36(4), 717-731.

Qureshi, J.A., Sarwat, N., Ali, R., \& Afridi, T. (2020). 'Ostracism and Work Attitudes: The Moderating Effects of Emotional Intelligence'. Pakistan Journal of Social Sciences (PJSS), 40(2), 961-971.

Rice, R. W., Frone, M. R., \& McFarlin, D. B. (1992). Work-nonwork conflict and the perceived quality of life. Journal of Organizational behavior, 13(2), 155-168.

Ryff, C. D. (1995). Psychological well-being in adult life. Current directions in psychological science, 99104.

Sarwat, N., \& Shahzad, K. (2017). An Investigation into the Role of Mindfulness on the Relationship between Hindering Job Demands and Stress-Related Presenteeism. Pakistan Journal of Social Sciences (PJSS), 37(2), 608-619.

Shrout, P. E., \& Bolger, N. (2002). 'Mediation in experimental and nonexperimental studies: new procedures and recommendations'. Psychological Methods, 7(4), 422.

Staines, G. L. (1980). Spillover versus compensation: A review of the literature on the relationship between work and nonwork. Human relations, 33(2), 111-129.

Steger, M. F., Dik, B. J., \& Duffy, R. D. (2012). Measuring meaningful work: The work and meaning inventory (WAMI). Journal of career Assessment, 20(3), 322-337. 